\title{
Diagnostic Reliability of the American College of Radiology Thyroid Imaging Reporting and Data System in Royal Commission Hospital, Kingdom of Saudi Arabia
}

\author{
Hussain Alyousif(D, Mona A. Sid Ahmed (D), Ayat Al Saeed (D, Abdulmohsin Hussein (D), Imad Eddin Musa*(D) \\ Department of Internal Medicine, Royal Commission Hospital, AL Jubail Industrial City, Al Jubail, Kingdom of Saudi Arabia
}

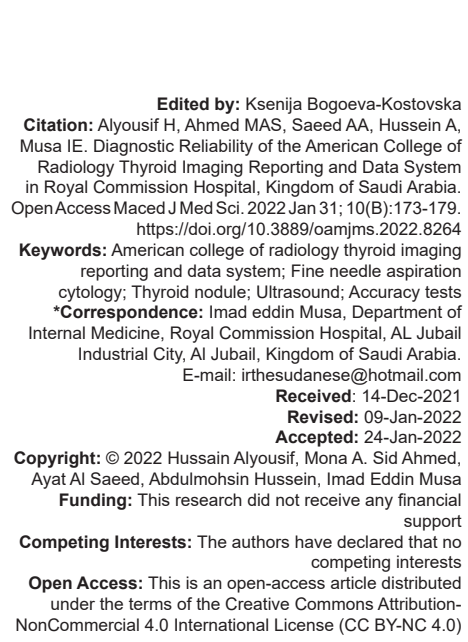

\section{Introduction}

The incidence of thyroid tumors continues to increase worldwide [1] and represents the most prevalent endocrine cancer globally [2]. A similar increase in thyroid cancer was observed in the Kingdom of Saudi Arabia (KSA) and other Gulf countries [3], [4]. The presence of an abnormal lesion within the thyroid gland tissue is called a thyroid nodule [5]. Thyroid ultrasonography is the primary non-invasive modality used for evaluating thyroid nodules [6]. A thyroid ultrasound scan improves the diagnostic rate of thyroid nodules (50-60\%) [7]. Classification and scoring systems are utilized to improve the diagnostic capacity of thyroid ultrasound scans. The American College of Radiology Thyroid Imaging Reporting and Data System (ACR TI-RADS) is one thyroid scoring system that is used to assess thyroid nodules and to predict those with malignant potential: the higher the score, the higher the malignancy risk [8]. The malignancy risk of thyroid nodules using ACR TI-RADS is predicted by ultrasound patterns: combining solidity, echogenicity, and suspicious ultrasound features [9]. The suspicious features of thyroid nodule ultrasound, such as microcalcification, a nodule that is taller than it is wide and speculated or microlobulated margins, are considered to be independent predictors of malignancy in a solid or hypoechoic nodule [9]. However, thyroid fineneedle aspiration cytology (FNAC) remains the gold standard for evaluating thyroid nodular disorders [10]. Sonography-guided thyroid FNAC augments the accuracy and safety of the procedure for assessing thyroid nodules [11]. Additionally, the Bethesda System for Reporting Thyroid Cytology (TBSRTC) is an important and reliable scoring classification system that improves diagnostic accuracy [12]. Applying ACR TI-RADS criteria can minimize the number of ultrasound-guided FNACs performed on benign nodules [13]. Hence, many studies have assessed ACR TI-RADS to determine its sensitivity, specificity, positive predictive value, negative predictive value, accuracy rate and receiver operating characteristic (ROC) curves [14], [15], [16], [17], [18], [19], [20], [21], [22]. Thyroid ultrasound is a reliable non-invasive, practical method [6], [23]; it is accessible and has a low capital 
cost [6]. Recently, published studies conducted in KSA have documented an increase in the thyroid cancer rate $(9-11.7 \%)$ [4], [24] with a significant geographical variation across the different areas of KSA [4], [25], [26]. Despite the wide use and importance of thyroid ultrasound as an essential diagnostic tool, along with marked improvements in reporting systems globally and the trend of the increasing prevalence of thyroid cancer, few studies have published data assessing the accuracy of ACR TI-RADS in KSA. Hence, the current study aimed to investigate the accuracy of ACR TI-RADS and its associated factors among adult patients at the Royal Commission Hospital in eastern KSA.

\section{Methods}

A retrospective study was conducted at the Royal Commission Hospital from January 1, 2017 , through September 31, 2021. The Royal Commission Hospital has 200 physicians in all major specialties and most subspecialties. It has a 217-bed capacity for inpatient care, as well as outpatient clinics and primary care services at many health centers throughout the city. We retrieved the medical records of patients (males and females), aged 18 years and older with documented thyroid nodules based on ultrasound findings who had undergone ultrasound-guided FNAC in the hospital. We excluded the medical records of patients with incomplete data, those who underwent partial thyroid surgery without prior thyroid FNAC, cases with known thyroid malignancy, patients diagnosed with thyroid cancer from a lymph node biopsy, and reports from other hospitals. The following data were collected in a questionnaire: age, gender, weight, and height to obtain the body mass index (BMI), thyroid status, and Vitamin D levels. High-resolution thyroid ultrasonography was performed in the radiology department by a specialist, then it was reviewed by a consultant radiologist before releasing the approved report. ACR TI-RADS was adopted for reporting the thyroid ultrasound scan, as seen in Table 1 [27]. The FNAC was done by an expert radiologist under ultrasound guidance. The procedure was performed after providing the patients with a proper explanation and obtaining their informed consent. Under aseptic conditions and application of a local anesthetic, a 22-gauge needle with a $10-\mathrm{mL}$ syringe was used to target the areas presumed to contain the most cellular material of the thyroid nodule under ultrasound guidance. Then, continuous low negative pressure was applied concomitantly with a to-and-fro movement of the needle within the lesion to obtain material from the tissues of the thyroid nodule in the needle hub. Mild pressure was applied to prevent bleeding at the site of the needle puncture, then the patient was kept for 15 minutes before being reassured and discharged. The slides were prepared using a method similar to
Table 1: TI-RADS

\begin{tabular}{ll}
\hline Category definitions & \\
\hline TI-RADS -1 & Normal thyroid gland \\
TI-RADS -2 & Benign nodule \\
TI-RADS -3 & Highly probable benign nodule \\
TI-RADS -4 & Suspicion for malignancy \\
TI-RADS -5 & Malignant nodule with more than two criteria of high suspicion \\
\hline
\end{tabular}

what is used for blood smears: one drop of aspirated material was forced onto each of several glass slides and the smears were prepared by using a second glass slide. The labeled slides were transferred to the histopathology department in the hospital after being fixed with $95 \%$ ethanol. A final cytopathology report was issued after each cell block was evaluated by an expert histopathologist. The outcome of the ultrasoundguided thyroid FNAC was reported using the 2017 TBSRTC [28], as seen in Table 2. All the thyroid nodules were evaluated by ultrasound and the nodules with an ACR TI-RADS classification were categorized into four groups (2, 3, 4, and 5). Patients with ACR TI-RADS 1 (normal thyroid gland) were excluded as there was no indication to subject them for FNAC. The results of the thyroid ultrasound scan were grouped in two categories according to diagnostic ability of the ACR TIRADS/The TBSRTC systems in distinguishing thyroid nodules that required or not FNAC and the potential risk of malignancy as reference standard ( $\angle A C R$ TIRADS 3/The TBSRTCIII vs. $\geq A C R$ TIRADS 3/The TBSRTC III) [29]: low risk (ACR TI-RADS 2 [Not suspicious] and potential highrisk ACR TI-RADS 3 [Mildly suspicious]) (ACR TI-RADS 4 [Moderately suspicious] and ACR TI-RADS 5 [Highly suspicious]). The TBSRTC outcome of the thyroid FNAC was obtained for each group as illustrated in (Figure 1). Then, the remaining results of thyroid FNAC were assigned to two groups based on the potential risk of malignancy: low risk for malignancy (I-II) and high risk for malignancy (III-VI) to assess the accuracy of the ARC TI-RADS scoring system.

\begin{tabular}{|c|c|}
\hline $\begin{array}{l}\text { I. Non-diagnostic or } \\
\text { Unsatisfactory }\end{array}$ & $\begin{array}{l}\text { Cyst fluid only, virtually acellular specimen and } \\
\text { other (obscuring blood, clotting artifact etc) }\end{array}$ \\
\hline $\begin{array}{l}\text { II. Benign } \\
\text { II }\end{array}$ & $\begin{array}{l}\text { Consistent with a benign follicular nodule (includes } \\
\text { adenomatoid nodule, colloid nodule, etc), consistent with } \\
\text { lymphocytic (Hashimoto) thyroiditis in the proper clinical } \\
\text { context or consistent with granulomatous (subacute) } \\
\text { thyroiditis }\end{array}$ \\
\hline $\begin{array}{l}\text { III. Atypia of Undetermined } \\
\text { Significance }\end{array}$ & Follicular lesion of undetermined significance \\
\hline IV. Follicular Neoplasm & $\begin{array}{l}\text { Suspicious for a follicular neoplasm or specify if Hürthle } \\
\text { cell (oncocytic) type }\end{array}$ \\
\hline $\begin{array}{l}\text { V. Suspicious for } \\
\text { Malignancy }\end{array}$ & $\begin{array}{l}\text { Suspicious for one of these cancer; papillary carcinoma or } \\
\text { medullary carcinoma or metastatic carcinoma or lymphoma } \\
\text { or other cancer }\end{array}$ \\
\hline VI. Malignant & $\begin{array}{l}\text { Diagnostic for one of these: Papillary thyroid carcinoma, } \\
\text { poorly differentiated carcinoma, medullary thyroid } \\
\text { carcinoma, undifferentiated (anaplastic) carcinoma, } \\
\text { squamous cell carcinoma, carcinoma with mixed } \\
\text { features (specify), metastatic carcinoma, non-Hodgkin } \\
\text { lymphoma or other }\end{array}$ \\
\hline
\end{tabular}

\section{Statistical Analysis}

Data were analyzed using SPSS for Windows (version 22.0). Continuous data were checked for 


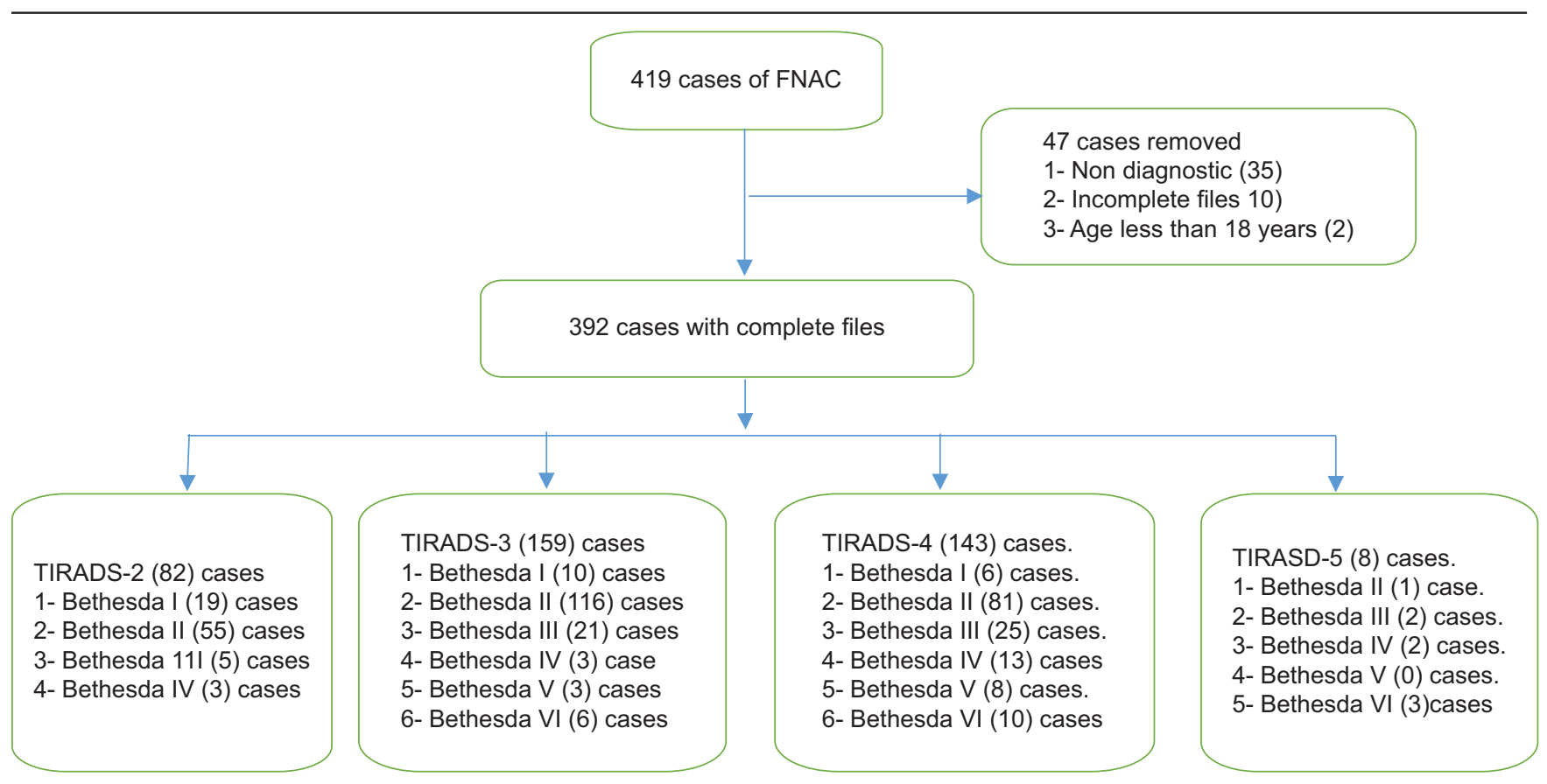

Figure 1: Inclusion and exclusion criteria

normality using the Shapiro-Wilk test, and none of the data were normally distributed. Data were expressed as proportions, the mean (Standard deviation [SD]), or as number (proportion), as applicable. The characteristic features were obtained: age, gender, thyroid status, thyroid function test, and Vitamin D level. Diagnostic accuracy tests were performed using a 4-grid cell to calculate the sensitivity, specificity, positive predictive value, negative predictive value, and ROC curves. The ROC curves were used to compare sensitivity and specificity. A larger area under the ROC curves was associated with a higher diagnostic accuracy.

\section{Results}

Three hundred and ninety-two patients who underwent a thyroid ultrasound scan and ultrasoundguided thyroid FNAC were enrolled in the study. The mean (SD) age was 46.03 (13.96) years, and $332(84.7 \%)$ were females. The mean (SD) of BMI was $31.90(22.32) \mathrm{kg} / \mathrm{m}^{2}$ and vitamin D $17.65(11.15) \mathrm{nmol} / \mathrm{L}$. The mean (SD) for thyroid function test was $5.37(44.16)$ $\mathrm{mmol} / \mathrm{L}$ for thyroid-stimulating hormone, $1.48(1.49) \mathrm{ng} /$ $\mathrm{dL}$ for free thyroxine (FT4), and $2.69(0.70) \mathrm{nmol} / \mathrm{L}$ for free triiodothyronine (FT3) (Table 3). Most of the participants were euthyroid (63.8\%), but $28.6 \%$ had hypothyroidism and $7.7 \%$ had hyperthyroidism. The thyroid ultrasound reports for ACR TI-RADS groups 2, 3, 4, and 5 were $(21.0 \%),(40.6 \%),(36.4 \%)$ and $(2.0 \%)$, respectively. The outcome of the thyroid FNAC based on the TBSRTC reporting system was non-diagnostic (8.9\%), benign in $64.4 \%$ of the cases, atypia of undetermined significance in $13.5 \%$ of the cases, follicular neoplasm in $5.4 \%$ of the cases, suspicious for malignancy in $2.8 \%$ of the cases and malignant in $4.8 \%$ of the cases. The accuracy tests results were sensitivity $(92.3 \%)$, specificity $(25.7 \%)$, positive predictive value $(32.2 \%)$, and negative predictive value (87.5\%), (Table 4).

Table 3: General characteristics of patients who underwent thyroid ultrasound and FNAC in eastern region 2017-2021

\begin{tabular}{lll}
\hline Variables & Mean & Standard deviation \\
\hline Age, years & 46.0306 & 13.96063 \\
Body mass index, $\mathrm{kg} / \mathrm{m}^{2}$ & 31.9025 & 22.31620 \\
Thyroid-stimulating hormone, $\mathrm{mmol} / \mathrm{L}$ & 5.3718 & 44.16181 \\
Free triiodothyronine, nmol/L & 2.6893 & 0.70443 \\
Free thyroxine, $\mathrm{ng} / \mathrm{dL}$ & 1.4773 & 1.49466 \\
Vitamin D, nmol/L & 17.6470 & 11.14719 \\
Gender & Number & Proportion \\
$\quad$ Female & 332 & 84.7 \\
$\quad$ Male & 60 & 15.3 \\
Thyroid status & & \\
$\quad$ Euthyroid & 250 & 63.8 \\
$\quad$ Hypothyroidism & 112 & 28.6 \\
$\quad$ Hyperthyroidism & 30 & 7.7 \\
\hline
\end{tabular}

While ACRTI-RADS 2 demonstrated nonmalignant changes on FNAC findings (Bethesda I (32.9\%) vs. Bethesda II (67.1\%), ACRTI-RADS 5 showed evidence of malignant changes in $87.5 \%$ of the group.

Table 4: Sensitivity and specificity of ACT TI-RADS for patients who underwent thyroid ultrasound and FNAC in eastern region 2017-2021

\begin{tabular}{ll}
\hline Test & Result $\%$ \\
\hline Sensitivity & 92.3 \\
Specificity & 25.7 \\
Positive predictive value & 32.2 \\
Negative predictive value & 87.5 \\
\hline FNAC: Fine needle aspiration cytology. &
\end{tabular}

The sensitivity and specificity of the diagnosis for ARC TI-RADS were $87.7 \%$ and $65.2 \%$, respectively (area under the curve $[A U C]=0.590,95 \%$ $\mathrm{Cl}=0.530-0.650, \mathrm{p}<0.006)$, as seen in Figure 2 . 


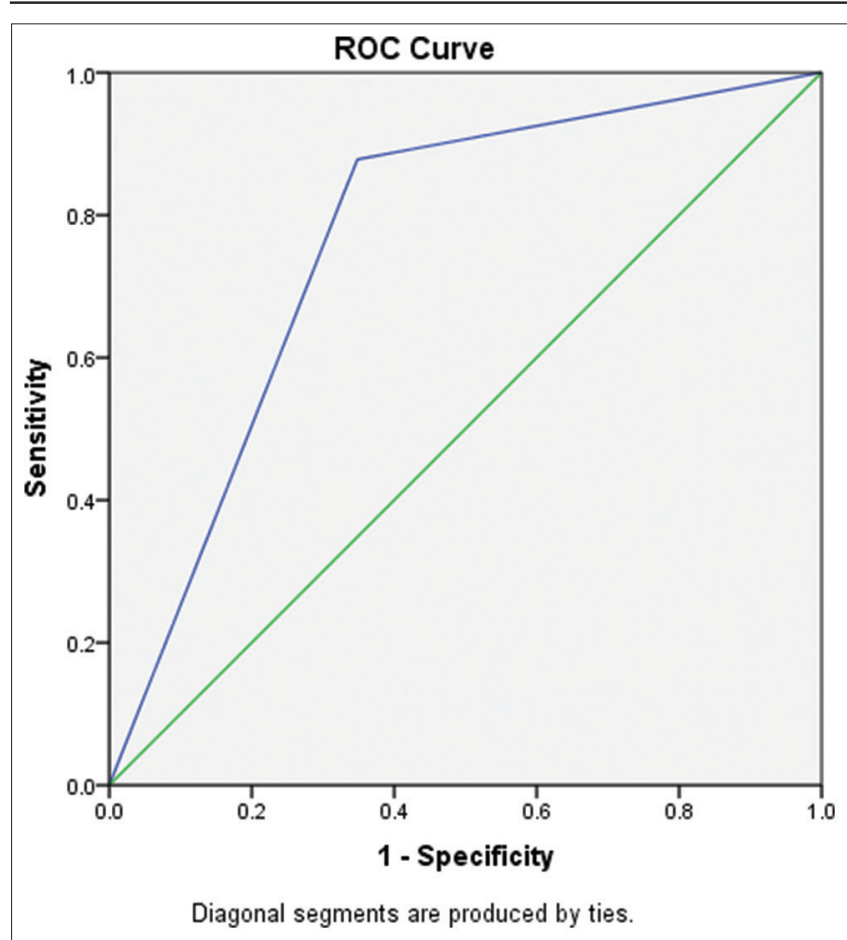

Figure 2: Receiver operating characteristic curve analysis of American College of Radiology Thyroid Imaging Reporting and Data System and the outcome of fine needle aspiration cytology (FNAC) (the Bethesda System for Reporting Thyroid Cytology) of patients who underwent thyroid ultrasound and FNAC in eastern region 2017-2021

\section{Discussion}

The main findings of our study regarding the accuracy of predicting malignancy risk based on a thyroid ultrasound reporting system (ACR TI-RADS) and the outcome of FNAC (TBSRTC classification) were: sensitivity $(92.3 \%)$, specificity $(25.7 \%)$, positive predictive value $(31 \%)$, negative predictive value $(87.5 \%)$ and $\mathrm{AUC}=0.765,95 \% \mathrm{Cl}=0.590,95 \%$ $\mathrm{Cl}=0.530-0.650, \mathrm{p}<0.006$. Our results showed that ACR TI-RADS had a significantly superior diagnostic accuracy (sensitivity and positive predictive value) for the risk of malignancy in comparison to the results obtained from a study conducted recently in central of KSA (Qassim): sensitivity (75\%) and positive predictive value $(15.7 \%)$ [30]. On the other hand, we documented almost equal AUC $=0.60(95 \%$ $\mathrm{Cl}: 0.505-0.713)$ besides relatively lower specificity and negative predictive value than that obtained in KSA (Qassim), which were $(62.35 \%)$ and $(96.3 \%)$ respectively [30]. The sensitivity and specificity results obtained in our study were comparable to the results documented in a systematic review and meta-analysis study that evaluated 37,585 and 10,926 nodules, respectively; the sensitivity and specificity were $70 \%$ and $89 \%$, respectively [31] and $98.3 \%$ and $55.2 \%$, respectively [32]. The sensitivity of ACRTI-RADS for predicting the risk of malignancy was markedly higher than that seen in Brazil (90\%) [15] Chile (88\%) [14]
China $(77.3 \%)$ [19], Malaysia $(85.7 \%)$ [22] Italy $(67.6 \%)$ [29] and $58.9 \%$ [33], Israel $86 \%$ [13] and Turkey $(76 \%)$ [34]. On the other hand a higher percentage of sensitivity was documented in different countries across the globe: Philippines (100\%) [35], China $(92.7 \%)$ [17] and (98.15\%) [18], Korea (95.5\%) [21] and (96.6\%) [20] and Egypt (98.3\%) [36]. In our study, the specificity of the ACRTI-RADS for predicting the risk of malignancy was lower than that reported in many different countries: obtained in Korea (58.6\%) [21] and (52.9\%) [20], Brazil (51.4\%) [15], China (47.84\%) [18] and $(89.1 \%)$ [19], Philippines (52.2\%) [36], Malaysia (51.1\%) [22] and (70.7\%) [17], Singapore (90.4\%) [16], Italy (57.2\%) [29] and 58.9\% [33], Egypt (90.9\%) [36] and Turkey (97.5\%) [34]. In the current study, the positive predictive value of the thyroid ACR TI-RADS was higher than that obtained in Italy (12.8\%) [29] and Philippines (16.5\%) [35], but lower than that found in Chile (49\%) [14], China (73.31\%) [18] and, Korea (44.5\%) [21] and Turkey (63.3\%) [34]. In our study, the negative predictive value ( $87.5 \%)$ for risk of malignancy in thyroid nodular disease based on ACRTI-RADS was higher than that obtained in China (85.1\%) [19]. Hence, this system may help reduce the rate of unnecessary thyroid FNAC. This was strengthened by markedly higher negative predictive value obtained in different studies conducted in different countries: Philippines (100\%) [35], Korea (96.9\%), Malaysia $(98.6 \%)$ [22] Italy (95.0 \%) [29], Brazil (94.7\%) [15], Chile (88\%), [14], China (94.65\%) [18] and Singapore $(93.8 \%)$ [16]. The AUC for ROC obtained in this study was almost similar to that obtained in a study conducted in Saudi Arabia (0.60) [30]. On the other hand, it was lower than the pooled AUC for ROC documented in a systematic review and meta-analysis study 0.938 [32] and in studies conducted in Korea (0.846) [20] and China (0.879) [19] and (0.817) [17]. The accuracy tests in our study and other studies indicated that ACR TI-RADS was a reliable noninvasive tool and a practical method for detecting the risk of malignancy in thyroid nodular disease, and it can prevent unnecessary FNAC and reduce the need for thyroid surgery when combined with the cytology result; it is also an appropriate method for screening and follow-up [21], [22], [23], [34], [36], [37]. The study documented non-malignant changes in ACRTIRADS 2 on FNAC findings (Bethesda I (32.9\%) versus Bethesda II (67.1\%). Moreover, ACRTIRADS 5 showed evidence of malignant changes in $87.5 \%$ of the group. The variability of accuracy tests in different studies may be explained by differences in the genetic backgrounds of the study groups and the influence of polygenetic factors, such as receptor tyrosine kinase/phenylthiocarbamide, the activation of oncogenes, such as Rat sarcoma, a human gene that encodes a protein called B-Raf and the overstimulation of the phosphatidylinositol 3-kinase/ protein kinase B pathway, which are involved in 
thyroid tumorigenesis [38]. Furthermore, genetic mutations have been primarily attributed to unknown aetiologies (about $80 \%$ ) [39]. Thus, these and other emerging molecular markers are used to provide additional approaches for classifying thyroid tumors and they may offer opportunities for developing novel approaches to tumor diagnosis, adding parameters for prognostic assessment, and stimulating potential biologic therapeutic strategies [39]. In fact, the recently updated TBSRTC has introduced molecular testing as a diagnostic adjunct to FNAC to avoid unnecessary surgery [28]. Moreover, malignant nodules with mixed echo patterns are scored lower in the ACR TI-RADS, resulting in misdiagnosis [8], which can affect the results of the accuracy tests. Additionally, thyroid ultrasound scans, the ultrasound-guided FNAC procedure, and cytology readings are operator dependent [40], which can impact the results. Moreover, differences in the methodologies adopted for these studies can influence the findings. Therefore, while thyroid ultrasound and FNAC are robust tools for evaluating thyroid nodular diseases, it is essential for physicians to continue to use their clinical judgment first and foremost when evaluating thyroid nodules [40].

This study had some limitations. First, it was a retrospective study, and the lack of ultrasound examination with the use of elastography and other factors were not assessed. In future studies, thyroid antibodies, iodine levels, nutritional pattern, genetic analysis, and environmental factors can be assessed.

\section{Conclusion}

ACR TI-RADS has a fair diagnostic accuracy value and higher negative predictive value, supporting its use as an important tool for assessing the risk of malignancy in thyroid nodules and reducing the need for unnecessary FNAC and thyroid surgery.

\section{Author Contribution}

Conceptualization: Hussain A Alyousif, Imad R Musa. Data curation: Mona A Sid Ahmed, Ayat Al Saeed, Abdulmuhsen Ali Ahmed Hussein. Formal analysis: Hussain A Alyousif Imad R Musa. Methodology: Hussain AAlyousif Imad R Musa. Project administration: Hussain A Alyousif Imad R Musa. Supervision: Imad R Musa. Validation: Mona A Sid Ahmed, Ayat Al Saeed, Abdulmuhsen Ali Ahmed Hussein. Visualization: Hussain A Alyousif Imad R Musa. Writing-original draft: Imad R Musa. Writing-review and editing: all investigators.

\section{References}

1. Kitahara CM, Sosa JA. The changing incidence of thyroid cancer. Nat Rev Endocrinol. Nat Rev Endocrinol. 2016;12(11):646-53. https://doi.org/10.1038/nrendo.2016.110 PMid:27418023

2. Bray F, Ferlay J, Soerjomataram I, Siegel RL, Torre LA, Jemal A. Global cancer statistics 2018: GLOBOCAN estimates of incidence and mortality worldwide for 36 cancers in 185 countries. CA Cancer J Clin. 2018;68(6):394-424. https://doi. org/10.3322/caac.21492

PMid:30207593

3. Alawadhi E, Al-Madouj A, Al-Zahrani A. Trends in thyroid cancer incidence in the gulf cooperation council states: A 15-year analysis. Gulf J Oncolog. 2020;1(34):31-8.

PMid:33431360

4. Hussain F, Iqbal S, Mehmood A, Bazarbashi S, ElHassan T, Chaudhri N. Incidence of thyroid cancer in the Kingdom of Saudi Arabia, 2000-2010. Hematol Oncol Stem Cell Ther. 2013;6(2):58-64. https://doi.org/10.1016/j.hemonc.2013.05.004 PMid:23756719

5. Cooper DS, Doherty GM, Haugen BR, Kloos RT, Lee SL, Mandel SJ, et al. Revised American thyroid association management guidelines for patients with thyroid nodules and differentiated thyroid cancer. Thyroid. 2009;19(11):1167-214. https://doi.org/10.1089/thy.2009.0110

PMid:19860577

6. Russ G, Bonnema SJ, Erdogan MF, Durante C, Ngu R, Leenhardt L. European thyroid association guidelines for ultrasound malignancy risk stratification of thyroid nodules in adults: The EU-TIRADS. Eur Thyroid J. 2017;6(5):225-37. https://doi.org/10.1159/000478927

PMid:2916776

7. Gharib H, Papini E, Garber JR, Duick DS, Harrell RM, Hegedüs L, et al. American association of clinical endocrinologists, American college of endocrinology, and associazione medici endocrinologi medical guidelines for clinical practice for the diagnosis and management of thyroid nodules--2016 update. Endocr Pract. 2016;22(5):622-39. https://doi.org/10.4158/EP161208.GL PMid:27167915

8. Shen Y, Liu M, He J, Wu S, Chen M, Wan Y, et al. Comparison of different risk-stratification systems for the diagnosis of benign and malignant thyroid nodules. Front Oncol. 2019;9:378. https:// doi.org/10.3389/fonc.2019.00378

PMid:31139568

9. Na DG, Baek JH, Sung JY, Kim JH, Kim JK, Choi YJ, et al. Thyroid imaging reporting and data system risk stratification of thyroid nodules: Categorization based on solidity and echogenicity. Thyroid. 2016;26(4):562-72. https://doi. org/10.1089/thy.2015.0460 PMid:26756476

10. Chua JM, Tang JYM, Lim DSW, Venkatanarasimha N Chandramohan S, Too CW, et al. Should we perform fine needle aspiration cytology of subcentimetre thyroid nodules? A retrospective review of local practice. Ultrasound. 2019;27(1):64-8. https://doi.org/10.1177/1742271X18820556 PMid:30774700

11. Bahaj AS, Alkaff HH, Melebari BN, Melebari AN, Sayed SI, Mujtaba SS, et al. Role of fine-needle aspiration cytology in evaluating thyroid nodules A retrospective study from a tertiary care center of Western Region, Saudi Arabia. Saudi Med J. 2020;41(10):1098-103. https://doi.org/10.15537/ smj.2020.10.25417

PMid:33026051 
12. Pandya A, Caoili EM, Jawad-Makki F, Wasnik AP, Shankar PR, Bude R, et al. Retrospective cohort study of 1947 thyroid nodules: A comparison of the 2017 American college of radiology TI-RADS and the 2015 American thyroid association classifications. AJR Am J Roentgenol. 2020;214(4):900-6. https://doi.org/10.2214/AJR.19.21904 PMid:32069084

13. Merhav G, Zolotov S, Mahagneh A, Malchin L, Mekel M, BeckRazi N. Validation of tirads ACR risk assessment of thyroid nodules in comparison to the ATA guidelines. J Clin Imaging Sci. 2021;11(1):37. https://doi.org/10.25259/JCIS_99_2021 PMid:34345527

14. Horvath E, Majlis S, Rossi R, Franco C, Niedmann JP, Castro A, et al. An ultrasonogram reporting system for thyroid nodules stratifying cancer risk for clinical management. J Clin Endocrinol Metab. 2009;94(5):1748-51. https://doi.org/10.1210/ jc.2008-1724 PMid: 19276237

15. de Macedo BM, Izquierdo RF, Golbert L, Meyer EL. Reliability of thyroid imaging reporting and data system (TI-RADS), and ultrasonographic classification of the American thyroid association (ATA) in differentiating benign from malignant thyroid nodules. Arch Endocrinol Metab. 2018;62(2):131-8. https://doi.org/10.20945/2359-3997000000018 PMid:29641731

16. Singaporewalla RM, Hwee J, Lang TU, Desai V. Clinicopathological correlation of thyroid nodule ultrasound and cytology using the TIRADS and bethesda classifications. World J Surg. 2017;41(7):1807-11. https://doi.org/10.1007/ s00268-017-3919-5

PMid:28251273

17. Tan $\mathrm{H}$, Li Z, Li N, Qian J, Fan F, Zhong H, et al. Thyroid imaging reporting and data system combined with Bethesda classification in qualitative thyroid nodule diagnosis. Medicine (Baltimore). 2019;98(50):e18320. https://doi.org/10.1097/ MD. 0000000000018320

PMid:31852120

18. Xue E, Zheng M, Zhang S, Huang L, Qian Q, Huang Y. Ultrasonography-based classification and reporting system for the malignant risk of thyroid nodules. J Nippon Med Sch. 2017;84(3):118-24. https://doi.org/10.1272/jnms.84.118 PMid:28724845

19. Lai S, Chen Y, Chen Z, Wang L, Cong S, Kuang J. Accuracy of two thyroid imaging, reporting and data systems for differential diagnosis of benign and malignant thyroid nodules. Nan Fang Yi Ke Da Xue Xue Bao. 2020;40(3):400-6. https://doi. org/10.12122/j.issn.1673-4254.2020.03.19 PMid:32376572

20. Xu T, Wu Y, Wu RX, Zhang YZ, Gu JY, Ye XH, et al. Validation and comparison of three newly-released thyroid imaging reporting and data systems for cancer risk determination. Endocrine. 2019;64(2):299-307. https://doi.org/10.1007/ s12020-018-1817-8

PMid:30474824

21. Ha EJ, Moon WJ, Na DG, Lee YH, Choi N, Kim SJ, et al. A multicenter prospective validation study for the Korean thyroid imaging reporting and data system in patients with thyroid nodules. Korean J Radiol. 2016;17(5):811-21. https://doi. org/10.3348/kjr.2016.17.5.811 PMid:27587972

22. Tan L, Tn YS, Tan S. Diagnostic accuracy and ability to reduce unnecessary FNAC: A comparison between four thyroid imaging reporting data system (TI-RADS) versions. Clin Imaging. 2020;65:133-7. https://doi.org/10.1016/j.clinimag.2020.04.029 PMid:32470834
23. Jabar AS, Koteshwara P, Andrade J. Diagnostic reliability of the thyroid imaging reporting and data system (TI-RADS) in routine practice. Pol J Radiol. 2019;84:e274-80. https://doi.org/10.5114/ pjr.2019.86823

PMid:31482001

24. Bazarbashi S, Al Eid H, Minguet J. Cancer incidence in Saudi Arabia: 2012 data from the Saudi cancer registry. Asian Pac J Cancer Prev. 2017;18(9):2437-44. https://doi.org/10.22034/ APJCP.2017.18.9.2437

\section{PMid:28952273}

25. Musa IR, El Khatim Ahmad M, Al Raddady FS, Al Rabih WR Elsayed EM, Mohamed GB, et al. Predictors of a follicular nodule (Thy3) outcome of thyroid fine needle aspiration cytology among Saudi patients. BMC Res Notes. 2017;10(1):612. https:// doi.org/10.1186/s13104-017-2943-8 PMid:29169383

26. Saeed MI, Hassan AA, Butt ME, Baniyaseen KA, Siddiqui MI, Bogari NM, et al. Pattern of thyroid lesions in Western Region of Saudi Arabia: A retrospective analysis and literature review. J Clin Med Res. 2018;10(2):106-16. PMid:29317955

27. Tessler FN, Middleton WD, Grant EG, Hoang JK, Berland LL, Teefey SA, et al. ACR thyroid imaging, reporting and data system (TI-RADS): White paper of the ACR TI-RADS committee. J Am Coll Radiol. 2017;14(5):587-95. https://doi.org/10.1016/j. jacr.2017.01.046

PMid:28372962

28. Cibas ES, Ali SZ. The 2017 bethesda system for reporting thyroid cytopathology. Thyroid. 2017;27(11):1341-6. https://doi. org/10.1089/thy.2017.0500

PMid:29091573

29. Seminati D, Capitoli G, Leni D, Fior D, Vacirca F, Di Bella C, et al. Use of diagnostic criteria from ACR and EU-TIRADS systems to improve the performance of cytology in thyroid nodule triage. Cancers (Basel). 2021;13(21):5439. https://doi.org/10.3390/ cancers 13215439

PMid:34771602

30. Ewid M, Naguib M, Alamer A, El Saka H, Alduraibi S, AlGoblan A et al. Updated ACR thyroid imaging reporting and data systems in risk stratification of thyroid nodules: 1-year experience at a tertiary care hospital in Al-Qassim. Egypt J Intern Med. 2020;31(4):868-73. https://doi.org/10.4103/ejim.ejim_143_19

31. Kim DH, Chung SR, Choi SH, Kim KW. Accuracy of thyroid imaging reporting and data system category 4 or 5 for diagnosing malignancy: A systematic review and meta-analysis. Eur Radiol. 2020;30(10):5611-24. https://doi.org/10.1007/ s00330-020-06875-w

PMid:32356157

32. Migda B, Migda M, Migda MS, Slapa RZ. Use of the kwak thyroid image reporting and data system (K-TIRADS) in differential diagnosis of thyroid nodules: Systematic review and meta-analysis. Eur Radiol. 2018;28(6):2380-8. https://doi. org/10.1007/s00330-017-5230-0

PMid:29294156

33. Leni D, Seminati D, Fior D, Vacirca F, Capitoli G, Cazzaniga L, et al. Diagnostic Performances of the ACR-TIRADS system in thyroid nodules triage: A prospective single center study. Cancers (Basel). 2021:13(9):2230. https://doi.org/10.3390/ cancers 13092230 PMid:34066485

34. Stoian D, Timar B, Derban M, Pantea S, Varcus F, Craina M, et al. Thyroid Imaging Reporting and Data System (TI-RADS): The impact of quantitative strain elastography for better stratification of cancer risks. Med Ultrason. 2015;17(3):327-32. https://doi.org/10.11152/mu.2013.2066.173.dst 
PMid:26343081

35. Gacayan RJ, Kasala R, Puno-Ramos MP, Mojica DJ, Castro MK. Comparison of the diagnostic performance of ultrasound-based thyroid imaging reporting and data system (TIRADS) classification with American thyroid association (ATA) guidelines in the prediction of thyroid malignancy in a single tertiary Center in Manila, Philippines. J ASEAN Fed Endocr Soc. 2021;36(1):69-75. https://doi.org/10.15605/jafes.036.01.14 PMid:34177091

36. Basha MA, Alnaggar AA, Refaat R, El-Maghraby AM, Refaat MM, Abd Elhamed ME, et al. The validity and reproducibility of the thyroid imaging reporting and data system (TI-RADS) in categorization of thyroid nodules: Multicentre prospective study. Eur J Radiol. 2019;117:184-92. https://doi.org/10.1016/j. ejrad.2019.06.015

PMid:31307646

37. Yun G, Kim YK, Choi SI, Kim JH. Medullary thyroid carcinoma:
Application of thyroid imaging reporting and data system (TI-RADS) classification. Endocrine. 2018;61(2):285-92. https:// doi.org/10.1007/s12020-018-1594-4

PMid:29680915

38. Cortés JMR, Zerón HM. Genetics of thyroid disorders. Folia Med (Plovdiv). 2019;61(2):172-9. https://doi.org/10.2478/ folmed-2018-0078

PMid:31301652

39. Rebaï M, Rebaï A. Molecular genetics of thyroid cancer. Genet Res (Camb). 2016;98:e7. https://doi.org/10.1017/ S0016672316000057

PMid:27174043

40. Le AR, Thompson GW, Hoyt BJ. Thyroid fine-needle aspiration biopsy: An evaluation of its utility in a community setting. J Otolaryngol Head Neck Surg. 2015;44(1):12. https://doi. org/10.1186/s40463-015-0063-9

PMid:25890284 